\title{
Designing markets for learning: a virtual trading room approach
}

\author{
J. R. O'Brien \\ Associate Professor of Accounting and Experimental Economics, \\ Tepper School of Business, Carnegie Mellon University
}

\begin{abstract}
The internet has opened up new opportunities to educators especially in terms of embracing constructivist approaches to learning. The objective of this paper is to describe how an interactive market approach to distant learning is designed and implemented in the Masters of Computational Finance (MSCF) program at Carnegie Mellon University. This approach provides a subtle blend of both behaviorist and radical constructivist principles applied to the learning environment. This resulted in a new solution to a problem facing educators, which is how to design and implement experiential settings that engage students to learn effectively.

Keywords: interactive financial markets, behaviorist, radical constructivist, educational trading rooms, distant learning.
\end{abstract}

\section{Introduction}

The internet is rapidly transforming our approach to education. It permits virtual worlds to be constructed in a manner that can deliver solutions to a major problem facing educators. This is:

"... to design a series of experiences for students that will enable them to learn effectively and motivate them to engage in the corresponding activities: On both of these points, disagreement between radical constructivists and other cognitive psychologists would be hard to find. The more difficult problem is determining the desirable learning goals and the experiences that, if incorporated in the instructional phase, will enable students to achieve these goals."

Anderson et al. [1, p238]. 
The objective of this paper is to describe the solution to this problem developed for the Masters of Computational Finance (MSCF) program at Carnegie Mellon University using the Financial Trading System (FTS) markets and cases. The Financial Trading System and the related concept of an educational trading room classroom was created by two professors at Carnegie Mellon University (John R. O'Brien and Sanjay Srivastava). The first trading room classroom was constructed in 1987, referred to as Simulab, and later this evolved into FAST (Financial Analysis and Securities Trading) program. In 1997 Professors O’Brien and Srivastava received a Smithsonian Institute award for the FAST program. System details are available at www.ftsweb.com.

Computational finance students enter the program with well developed computational skills but are often lacking in regards to the workings of financial markets, i.e., the subject matter of finance. We rectify this gap via a specially designed course that exploits interactive market experience to achieve desired learning goals with respect to important financial market concepts. In an interactive market approach the students are the trading crowd and course goals are tied to the price discovery problem facing the market. This teaching method exploits both behavioral and radical constructivist approaches to learning. The former because immediate feedback from repetitive market trials is exploited in the trading case. The latter because the students make up the trading crowd in a real market and are therefore responsible for formulating and implementing personal trading strategies that generate the market prices. This puts students in the position of having to first develop their own mental structures for the drivers of the price discovery process in a financial market in order to be able to trade successfully (Todd and Morris [4], Anderson et al. [1], Bruner [2], Fennimore and Tinzman [3]).

The remainder of this paper is as follows. Section 2 provides a general description an interactive market. Section 3 describes the learning goals for the course. Section 4 describes some of the results, and section 5 provides discussion and conclusions.

\section{Description of the interactive markets}

In this paper an interactive market refers to a market where the students are the trading crowd whose task it is to discover prices by implementing personal trading strategies in a competitive, real-time setting. An interactive market is distinct from a trading exercise that has students manage a position where prices are fed in from the real world markets. In this latter exercise, students do not interact with the real world trading crowd and therefore do not experience how their trades influence the price discovery process.

The trading case used in an interactive market is designed to let students attain course goals from personal trading experience. In this way the educational trading case bridges the gap between what is normally taught in traditional finance courses and an interactive market course. One trading trial may cover three years of calendar time in fifteen minutes. This allows a normal class session to repeat independent trading trials so that important behaviorist features 
such as immediate feedback/reinforcement and successive approximations are present in the learning environment. Radical constructivist, on the other hand emphasizes discovery learning, learning in complex situations, and learning in social contexts (Anderson et al. [1, p230]). Because no trades can take place until the trading crowd discover prices, students are placed into a setting that requires the construction of their own mental structures about what drives price.

After the multiple trading trials have been completed, class discussion follows. The learning goals are formally introduced in this discussion so that students can extend their understanding from personal trading experience. The lesson mixes elements of both constructivist and behaviorist schools of thought, which, as argued here, provides a strong solution to the problem raised at the beginning of this paper.

\section{Interactive markets: learning objectives}

The two major objectives are, i. to understand how financial markets discover prices, and ii. what the major economic drivers of this process are (e.g., impact of arbitrage, opportunity costs, time value of money and risk preferences).

\subsection{Educational trading case}

The trading case creates the physical market environment that students are put into. All learning objectives have to be explicitly designed into this environment. In the following sections we illustrate how this is done, but first the physical environment is described for one case example. In this example, one trading trial covers three years of calendar time and has four fixed income markets open as follows:

Table 1: $\quad$ Timing and magnitude of cash flows.

\begin{tabular}{|llll|}
\hline Financial & End of: & & \\
Instrument & Year 1 & Year 2 & Year 3 \\
Coupon Bond & $\$ 10$ & $\$ 10$ & $\$ 110$ \\
1-Year Zero & $\$ 100$ & & \\
2-Year Zero & & $\$ 100$ & \\
3-Year Zero & & & $\$ 100$ \\
\hline
\end{tabular}

One coupon bond pays $\$ 10$ at the end of each year and $\$ 110$ at the end of year 3 . Similarly, one 1-year zero pays $\$ 100$ at the end of year 1 and nothing thereafter and so on for the 2-year and 3-year zero coupon bonds as described above. In addition, there is a money market open that traders can borrow or lend to at $\mathrm{r} \%$ interest for the year.

We consider next how the course objectives relate to this environment. 


\subsection{Price discovery}

When the market first opens the trading screen is blank with respect to prices to motivate the following question: "If there are no prices how can we trade?" That is, there are no prices until someone in the trading crowd enters a "bid to buy" or "offer to sell" in accordance with the rules that govern trading in the market (i.e., the market microstructure). As a result, students must first master the operational details of the market microstructure. Once mastered, students are led naturally to the second important question: "What are reasonable prices to buy and/or sell at?" Answering this question gets students thinking about the drivers of the price discovery process in the following way.

\subsection{Arbitrage and the "Law of One Price"}

Consider a position (A) that has 10 coupon bonds in it. From table 1 provided in section 3.1 the future cash flows are $\$ 100$ (i.e., $10 * \$ 10=\$ 100$ ) at the end of years 1 and 2 , and $\$ 1100$ (i.e., $10 * \$ 110$ ) at the end of year 3. Now consider an alternative position (B) that consists of +1 1-year Zero +1 2-year Zero + 113 year Zeros. Both positions A and B have identical future cash flows in terms of both their timing and magnitude: Each position pays $+\$ 100,+\$ 100,+\$ 1100$ respectively at the end of years 1,2 , and 3 respectively. The law of one price implies that the price of $\mathrm{A}\left(\mathrm{P}_{\mathrm{A}}\right)$ must equal the price of $\mathrm{B}\left(\mathrm{P}_{\mathrm{B}}\right)$ :

If prices are unequal there exists a profitable trading strategy (i.e., an arbitrage opportunity) that consists of simultaneously buying low and selling high. As the trading crowd start exploiting these opportunities, all students get to experience important interactions between arbitrage and price discovery.

\subsection{Opportunity cost of capital}

A second fundamental concept in finance is the "Opportunity Cost of Capital." This concept asserts that the return from some investment opportunity (A) depends upon the return from the best available investment opportunity foregone if one proceeds with (A). Consider the following simple example.

Example: Consider buying a 1-year zero coupon bond for cash at a cost equal to $\$ \mathrm{P}_{\mathrm{Z1}}$. This requires withdrawing $\mathrm{P}_{\mathrm{Z} 1}$ from the money market and forgoing the riskless rate of interest $(\mathrm{r} \%)$ available for 1-year (i.e., the opportunity cost of capital). Thus, if buying the 1-year zero a trader should require at least a return equal to $\mathrm{r} \%$. Similarly, if selling the 1 -year zero coupon bond then $\mathrm{P}_{\mathrm{Z} 1}$ dollars are generated which are automatically deposited in the money market for $\mathrm{r} \%$ where $r \%>0$. As a result, in theory the buying price equals selling price and both equal $\$ 100 /(1+r \% / 100)$ when applying the concept of opportunity cost. This important concept immediately identifies the theoretical price for the 1-Year Zero in table 1, section 3.1. 


\subsection{The time value of money and the yield curve}

The previous example motivates another major concept in finance theory. This is the concept that $\$ 1$ today is not equivalent to $\$ 1$ tomorrow. This is clear because the beginning year price of the 1-year zero coupon bond must be less than the $\$ 100$ face amount received at the end of year. The time value of money permits future cash flows to be equated to a cash price paid today which formally is equal to the "present value" of the security when the discount rate equals the opportunity cost of capital.

In the market, traders observe the prices discovered and therefore can calculate and plot the implied discount rates from the 1-Year Zero, 2-Year Zero and 3-Year Zero prices against time to maturity. That is, they get to learn what the yield curve is and where it comes from.

\subsection{Risk preferences}

The example in section 3.4 applied the concept of opportunity costs to deduce the price of a bond that has 1-year of life remaining. However, suppose at the beginning of year 1 traders want to estimate the price of the 2-year zero coupon bond?

The immediate problem that arises is that the money market rates of interest for years 2 and 3 are not known at the beginning of year 1. Instead only the set of possible rates are known. Now students are confronted with the following decision: "Which do you prefer? Buy a 2-year zero coupon bond to earn a sure return vs. Leave an equivalent amount in the money market for two years. This amount earns the 1-year spot rate of interest during the first year and in year 2 it earns interest that depends upon what the realized year 2 money market rate is."

The answer to the preference question depends upon the concept of "risk aversion." From a risk assessment perspective there are three types of traders (i, ii, iii). Type $\mathrm{i}$ is averse to risk and requires the return from the rolling over money market strategy to exceed the implied return from buying a 2-year zero coupon bond at the beginning of year 1. Trader ii is neutral with respect to risk and therefore would equate the return from the 2-year zero coupon bond to the expected return from the rolling over in the money market strategy. Type iii is a risk loving trader. This trader type is happy to receive lower expected return from the rolling over in the money market strategy because they like assuming risk. As a result, by discovering prices in the trading session also reveals the trading crowd's risk preferences.

\section{Results from the interactive markets}

The trading course finished with a trading competition, conducted over two rounds on the internet with sponsored prize money provided by a major bank on Wall Street. This made the trading decisions real to the students from an economic perspective. Relative to the trading objective for the case (e.g., managing both risk and return) performance is immediately evaluated at the end 
of each trading trial. Two major measures employed are average rank in the trading crowd across repeated trading trials and cumulative dollar trading bonus.

Those traders who amass a cumulative negative bonus provide a clear signal that there is either a lack of understanding of important concepts or their trading implementation is poor. To gain insight into which applies, additional analysis is conducted at an individual level. This is in terms of the nature of the trading market making versus market taking.

A market maker is a trader who submits a bid to buy or an ask to sell a security. That is, market makers are actively involved in the price discovery process. A market taker is a trader who sells to an existing bid or buys from an existing ask. Trading exercises are varied to provide more or less emphasis upon these two roles. For example, when the price discovery problem is difficult the potential advantage shifts to the market maker, and when the price discovery process is relatively more transparent the potential advantage shifts towards the market taker/arbitrage trader. In this course students were deliberately exposed to both types of trading exercises (round 1 favored the market taker and round 2 favored the market maker).

\subsection{Individual performances: market making vs. market taking}

In Figures 1 and 2 below traders are ranked from first to last in terms of their performance across the two rounds of the competition. Traders from around 60 to higher managed to consistently lose money.

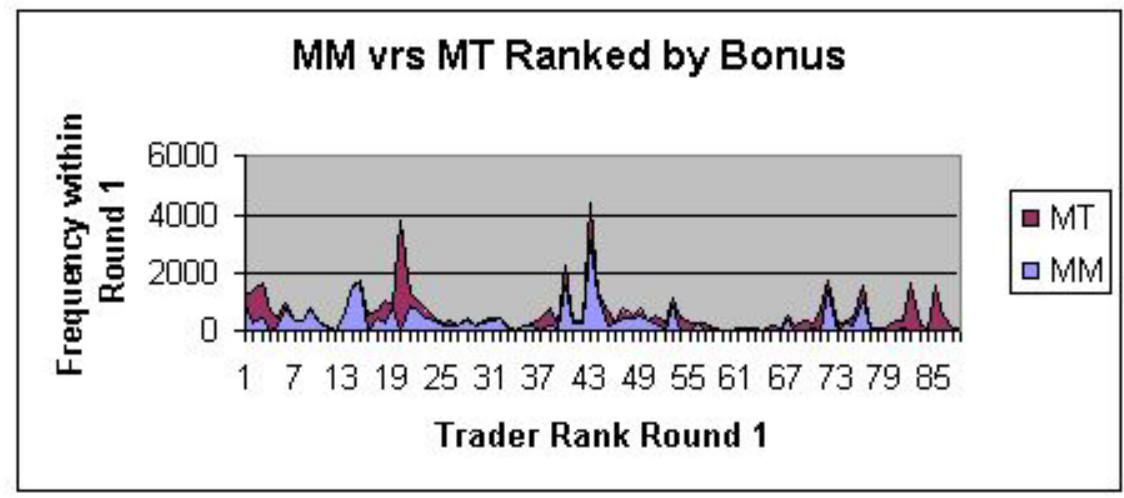

Figure 1: $\quad$ Frequency of market making versus market taking trades by trader performance in round 1 .

In round 1 it is clear that the very top traders and the very bottom traders were market takers (MT) whereas in round 2 the top traders were market makers (MM) as predicted. That is, the top traders are able to both design and implement a successful trading strategy. The very top trader (who finished number 1 in both rounds) exhibited skills in both market making and market taking. 


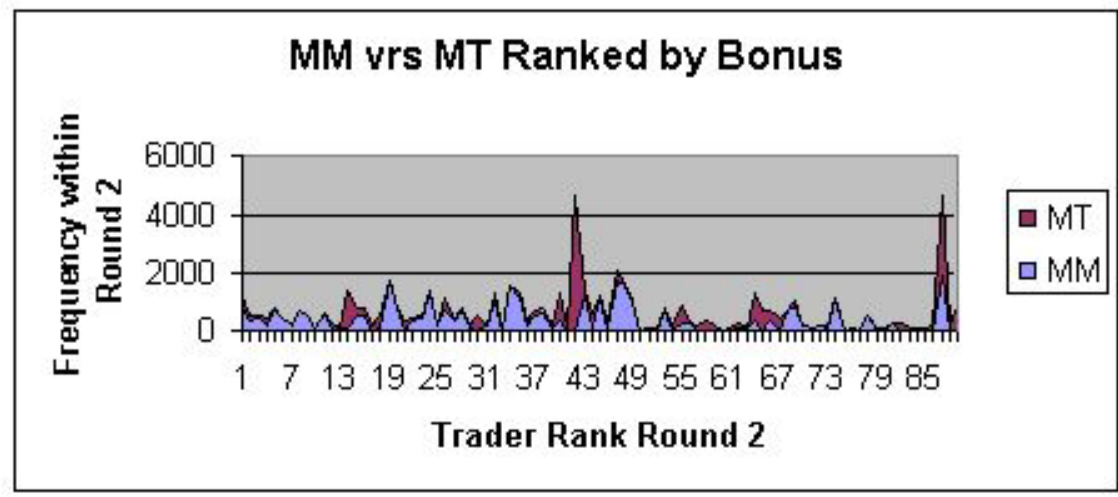

Figure 2: $\quad$ Frequency of market making versus market taking trades by trader performance in round 2 .

One major advantage of the interactive market approach to learning is that individual performance is both transparent and immediate. By the end of a session it is clear to both students and instructors who performed well and badly. In figures 1 and 2 recall that traders ranked higher than sixtieth consistently lost money. This reveals one of the following. Poor trading strategy design, poor implementation or both. Poor design is related to a lack of understanding of the economic drivers of the price discovery. Poor implementation is usually related to a lack of understanding of the market microstructure. That is, performance in the market immediately relates to one of the two major learning objectives for the course. In addition, because all transactions are recorded, trades can be checked for their consistency with each of the major learning objectives at an individual student level.

\section{Discussion and conclusions}

To summarize, interesting differences arise when teaching finance from a trading perspective as opposed to the traditional classroom setting. First, students are required to understand and apply concepts to a relatively "real world" problem. They learn there is a difference between theory and practice. Although the theory is relevant for designing trading strategies, it becomes clear to students that large individual differences exist when implementing trading strategies. Understanding this is a valuable lesson for students who plan to work in the field of finance. Second, with this teaching technique the instructor gives up control over outcomes. That is, instructors must adapt to a setting that promotes discussion geared towards potential explanations of unexpected outcomes. Combined the first and second points demonstrate to students that finance theory provides strong guidance and focuses students upon asking relevant questions even if the theory is incomplete and does not provide all of the answers. That is, the virtual market experience helps students to become well rounded from a finance practitioner's perspective. 
Finally, the interactive market setting from an educator's perspective provides a unique blend of applying both radical constructivist and behaviorist principles to the learning environment. That is, radical constructivism by using discovery learning in a complex social environment, and behaviorism by using immediate feedback and systematic evaluation of the learning goals. In this way the strengths of both approaches are drawn upon in the course design.

\section{References}

[1] Anderson, J. R., Reder, L. M. \& Simon, H., Radical constructivism and cognitive psychology. In D. Ravitch (Ed.) Brookings papers on education policy Washington, DC: Brookings Institute Press pp. 227-278, 1998.

[2] Bruner J. S., (2000) Acts of Meaning, Four Lectures on Mind and Culture, Cambridge MA: Harvard University Press

[3] Fennimore T.F., \& Tinzman M.B., What is a Thinking Curriculum North Central Regional Educational Laboratory, Oak Brook, 1990 online www.ncrel.org/sdrs/areas/rpl_esys/thinking.htm

[4] Todd, J.T., \& Morris, E.K., (eds). Modern perspectives on B.F. Skinner and contemporary behaviorism Greenwood Press, Westport, Connecticut London. : 1995.

[5] Using FTS in the Classroom, Financial Trading System, http://www.ftsweb.com/classroom.htm 